\title{
BLANCURA, COSMOPOLITISMO Y REPRESENTACIÓN EN GUATEMALA ${ }^{1}$
}

\author{
Jorge Ramón González Ponciano \\ Centro de Estudios Mayas, IIFL, UNAM
}

En la larga historia de las relaciones serviles en Guatemala, ser sirviente o cholero ha sido asociado al hecho de ser indio, pobre y no-blanco. ${ }^{2}$ Las clases altas y medias a menudo auto-representadas como gente decente, blanca o ladina, utilizan el término cholero para denigrar a los sirvientes y ridiculizar a la gente corriente, a quien consideran social, cultural y racialmente inferior. En este artículo examino algunas de las razones que provocaron durante los años recientes, la exacerbación del sentimiento racista y clasista en contra de ladinos e indígenas de las capas medias bajas y populares, estigmatizados como choleros, shumos y/o mucos. Como asunto de representación y guerra simbólica, el sentimiento anti-cholero, anti-shumo y anti-muco es un importante factor ideológico que facilita la reproducción de las relaciones serviles y las reglas no escritas de la blancura, que establecen cuál es el lugar que cada quien debe ocupar en sociedad en Guatemala. La blancura, más allá del fenotipo, constituye una ideología transnacional, interclasista e interétnica cuyos repertorios tienden a reforzar los principios del darwinismo social, la ley de sobrevivencia del más fuerte o del que, por linaje, género, religión, raza, clase o nacionalidad, tiene derecho "natural" a hacer menos, dominar, someter o eliminar a los demás (Allen, 1997; BonillaSilva, 1997 y 2000; Delgado, 1995; Frankenberg, 1993; Press Giroux, 1997; Goldberg, 1995; Harrison, 1995; Horne, 1999; Lipsitz, 1999; Omi y Winant, 1986, y Roediger, 1995).

Si la década de los años ochenta se caracterizó en Guatemala por la insurgencia guerrillera y el genocidio, la década de los noventa fue la del auge de

\footnotetext{
${ }^{1}$ Este artículo es una versión de la conferencia presentada durante el VI Congreso Internacional de Estudios Mayas en la ciudad de Villahermosa, Tabasco, el 15 de julio de 2004.

${ }^{2}$ Según Otto Schumann, el uso del término cholero en Guatemala se remonta a la época de la conquista de los choles, en 1695, cuando se les llevaba como sirvientes a Chamic, Chiapas y Santa Cruz El Chol, Baja Verapaz, en Guatemala. Otra acepción es la que se usa entre chujes, kanjobales y jacaltecos para referirse a una entidad mágica que puede ayudarlos. Cholero, dice Schumann, era un tratamiento similar al de mayero para llamar al que habla maya, o tzeltalero al que habla tzeltal (comunicación personal, 22 de abril de 2004, México D. F.).

${ }^{3}$ Uno de los esfuerzos más notables por mostrar el arraigo del racismo cultural en Guatemala, son los estudios de Marta Elena Casáus Arzú (1992, 1998 y 1999), que vinculan el análisis del racismo con la existencia de una elite blanca casi nunca mencionada en las investigaciones realizadas por antropólogos nacionales y extranjeros en Guatemala.
} 
diversas expresiones racistas apoyadas en la blancura y en los sentimientos antiindígena y anti-mestizo popular. Esos sentimientos expresan el miedo étnico de los estratos altos y medios a las movilizaciones indígenas y a los cambios introducidos por la migración intranacional y transnacional, que le han dado mayor visibilidad a una muchedumbre joven y desprotegida, una mara carente de oportunidades educativas y laborales, y por lo tanto propensa a engrosar las maras territoriales. En este artículo examino algunas etiquetas étnicas y socio-racistas que no aparecen en los estudios antropológicos realizados en Guatemala, basados en las perspectivas de la dicotomía indígena-ladino, que a menudo invisibilizan la "cultura finquera" y la violencia simbólica de las relaciones serviles.

\section{La mara}

En la definición contemporánea del universo simbólico de lo joven en Guatemala es importante destacar la presencia histórica del concepto mara, el sentimiento de ser parte de la mara y la apropiación de ese concepto por jóvenes de las capas medias y hasta de la elite, que lo utilizan para referirse a territorios de lo social, donde se manifiesta una voluntad de "nosotrosidad" y un sentimiento de pertenencia colectiva, nacional y transnacional. Antes de que se convirtiera en un tratamiento grupal que identifica a delincuentes juveniles organizados, la mara fue equivalente a banda, grey, broza, raza, manga o piña, según algunas de las expresiones del caló local. El surgimiento de la mara como expresión contracultural de la juventud citadina guatemalteca a fines de los años cincuenta, intentó contener la represión del anticomunismo instaurado en el Estado a partir del derrocamiento de la revolución nacionalista de Juan José Arévalo y Jacobo Arbenz Guzmán en 1954. Marco Augusto Quiroa (2001) sitúa el origen de la mara como espacio de esa subjetividad contestataria a mediados de los cincuenta, cuando llegó a Guatemala la película Marabunta, protagonizada por Charlton Heston. Quiroa destaca el gregarismo contracultural de la mara, que sigue aludiendo a la voluntad popular y al espacio interclasista articulado alrededor de alguna demanda en contra del Estado. ${ }^{4}$ La mara era o es un

\footnotetext{
${ }^{4}$ Escrito en un caló en el que se mezclan palabras del castellano dialectal guatemalteco con otras inventadas por el autor. Quiroa (2001) describe con humorística ironía los usos contemporáneos del término:

Los chirices de la nueva ola y las patojas recién salidas del cascarón, tal vez no sepan el origen de la palabra mara, usada en la actualidad para designar con pelos y lunares a grupos de diferente índole y distinta conducta" [... Un peliculón con Charlton Heston llamado Marabunta, que trataba de colonias millonarias y neoliberales de hormigas canches, entre arrieras y zompopos, que cuando se les alborotaba el apellido implantaban en la selva amazónica la política de tierra arrasada, usando el método de aqueche (Ríos Montt) [...] "A resultas de eso, asociaciones y sindicatos, pandillas y grupos, adoptaron el vocablo para dirigirse a colectivos
} 
sustituto del llamado pueblo con énfasis en el pueblo joven ladino e indígena popular y urbano. ${ }^{5}$ Un concepto que alude a un fenómeno distinto al de las maras transnacionales que en años recientes han captado la atención de la prensa debido a su participación en las redes del crimen organizado en Centro y Norteamérica.

\section{Maras estudiantiles y maras territoriales}

Dentro del amplio espectro de manifestaciones sociológicas englobadas en el concepto mara, las maras estudiantiles fueron en Guatemala durante los años setenta parte de la identidad escolar de muchos estudiantes de institutos públicos y colegios privados, que anualmente se enfrentaban en encuentros de básquetbol en el gimnasio capitalino "Teodoro Palacios Flores". Como expresión del gregarismo escolar, el protagonismo público de las maras estudiantiles durante los años noventa, empezó a ser rebasado por las acciones de las maras territoriales formadas por jóvenes residentes en barrios y asentamientos populares, participantes en las protestas que llevaron a la destitución del presidente Jorge Serrano Elías en junio de $1993 .^{6}$

El marero territorial, más que el miembro de las maras estudiantiles, es quien reúne todos los atributos más aborrecidos por la supremacía autoritaria en Gua-

de buenas y malas costumbres. Muchachos obedientes a la ley del menor esfuerzo y ahorrativos al máximo, abreviaron la palabra cuteándola a mara como se conoce al sol de hoy. Es usada y abusada por chancles aguacateros de la zona viva, chicas fresa del Montemaruca, hierberos del cartel de El Gallito, diputados expertos en buscarle tres pies al gato e introducir mano de simio a deshoras de la noche y esforzados guajeros del basurero multifamiliar de la zona tres.

${ }^{5}$ Las maras, según Quiroa (ibid.):

han invadido todos los sectores de la sociedad sin respetar el nivel académico, filiación política, clase social, linaje aristocrático o pureza de sangre. Son multiétnicas asegún convenga, pluriabusadas en pagar con pisto del vecino y multidisciplinarias cortando parejo [...]. También existen maras gruesas entrándole de a gordo a secuestros forcivoluntarios, fugas increibles desde las puertas del mismísimo infiernito escuintleco, cambio de dueños de vehículo sin pedir permiso y reparto de nieve colombiana por gramo, onza, kilo y tonelada, en trailer o a granel. Maritas rascuaches de nivel parvulario especialistas en pasar el dos de bastos en camiochatarras y apretazones o puyar con tortilla tiesa en oscuranas marginales por donde el cachudo perdió el celular, la chamarra y el carné del partido de la manita.

${ }^{6}$ Véase "Cancelarán las matrículas de los estudiantes que estén holgando", La Hora, 6 de marzo de 1992; "Educación y Gobernación actuarán contra estudiantes", La Hora, 9 de marzo de 1992; "No permitirán más bochinches", Siglo Veintiuno, 10 de marzo de 1992; "No habrá contemplaciones para quienes infrinjan la ley", La Hora, 28 de abril de 1992. "84 estudiantes menores y 13 adultos capturados". 
temala. Dentro de los mareros territoriales, el marero pandillero es por lo general adicto al alcohol, el crack, la mariguana o los inhalantes, y utiliza la violencia para intimidar, robar o asesinar. ${ }^{7}$ La gran cantidad de crímenes, asaltos y agresiones atribuidos a mareros, cholos o pandilleros ha hecho que en la opinión pública se mantenga el clamor interclasista por una mano dura que los extermine y ejecute una "limpieza social", como la que el general Efraín Ríos Montt impuso tras el Golpe de Estado del 23 de marzo de 1982. El traslape de las maras estudiantiles y las maras territoriales, que también se dio en El Salvador, y el posterior protagonismo transnacional de las segundas (v. g. la Mara Salvatrucha), son dos de varios factores que favorecen a la delincuencia de los jóvenes indígenas y mestizos desempleados en Centroamérica. Como parte de esta criminalización, muchas veces el ser marero se utiliza como sinónimo del ser shumo, muco o cholero.

\section{Del problema del indio al problema de la juventud}

Hace más de 50 años, el principal problema para la construcción del Estado-nación y la democracia en América Latina era el llamado problema del indio. A este problema, que se esperaba sería solucionado por la integración social de los indígenas a la nación homogénea con ayuda de la antropología, se agregó luego el problema de la mujer. Posteriormente, la controversia sobre la modernización regresiva, simulada, fallida o pospuesta, se desplazó al universo conceptual del problema de la juventud. El discurso sobre la juventud como problema y no como la energía social fundamental para la construcción democrática, "criminaliza" a cientos de miles de desempleados que cada año se convierten en parte del

\footnotetext{
${ }^{7}$ Según un informe sobre las maras elaborado por la Asociación para el Avance de las Ciencias Sociales en Guatemala (Avancso, 2000), a finales de los años ochenta, el perfil del marero medio era: Joven, menor de veinte años, nacido y crecido en la ciudad; alfabeto y con algún grado de estudios, perteneciente a una familia pobre o de clase media, sin trabajo pero habiendo trabajado en puestos mal pagados, que usa drogas de forma habitual y roba para poder conseguirlas, procedente de una familia inestable, con padres o padrastros violentos, alcohólicos e incomunicativos, con malas experiencias escolares. "Un rasgo decisivo para entender su psicología, dice el informe: la mayoría siente que no tiene futuro". Aunque este estudio no aborda el factor étnico-racial en la definición de los considerados mareros, puede percibirse que en el imaginario dominante existe una separación simbólica entre el lugar metasociológico asignado a la "mara", el pasado de las "maras estudiantiles". el ser marero territorial y los nuevos códigos culturales adoptados por muchos jóvenes como resultado de la migración intranacional y transnacional. Muchos de los mareros viven en asentamientos como El Mezquital, en donde casi la mitad de los habitantes son menores de quince años y muchos de los adultos son albañiles, choferes, mecánicos, maestros, trabajadoras de maquilas, pequeños comerciantes, tortilleras, trabajadoras domésticas, enfermeras y vendedores. Cada mara maneja códigos propios que los diferencian entre sí y tiene una influencia territorial cuya defensa o control la lleva a involucrarse en peleas más o menos violentas con otras maras. Los hechos de violencia se incrementan de viernes a domingo, con el cobro del salario semanal y un mayor consumo de alcohol, tanto de jóvenes como de adultos.
} 
problema de la juventud, el último gran chivo expiatorio del capitalismo tardío en la periferia del mundo. La criminalización de la juventud y en particular de la juventud plebeya, no-blanca, cholera, shuma y muca, convierte al desempleado joven en vago, reforzando viejos mitos de la mentalidad dominante que atribuyen el origen de toda delincuencia a la proliferación de haraganes y viciosos. A ello hay que agregar el poder movilizador de las representaciones que legitiman el ejercicio de la mano dura, en contra de los jóvenes que por ser indígenas o mestizos de extracción popular, son considerados racial, social y culturalmente inferiores, y por lo tanto desechables.

La percepción de los estratos altos es que estos jóvenes choleros carecen de educación y son proclives a la delincuencia por tener tendencia a la holgazanería, están mal alimentados y, por lo tanto, difícilmente permanecerán en la escuela y mucho menos llegarán a la universidad. Para esos jóvenes desempleados o subempleados la única opción laboral es incorporarse a la denominada "economía informal” (Bastos y Camus, 1994; Pérez Sáinz, 1990; Roberts, 1968 y 1970), la delincuencia común o a cualquiera de las redes clientelares manejadas por militares involucrados en negocios ilícitos heredados de la contrainsurgencia.

En Guatemala, como en otros países del mundo, la construcción de lo joven o de la juventud se ha dado a través de representaciones históricamente orientadas a darle visibilidad a los jóvenes con acceso al cosmopolitismo tecnológico y cultural de la economía de exportación y al poder simbólico de la blancura que va mas allá del fenotipo y del colorismo que separa a los canches de los morenos. Así, el ser joven ha sido proyección del ser urbano local, capitalino, alfabeto, europeizado, blanco o mestizo, asumido no-indígena y observante de los valores de la civilización, el cristianismo, el mercado y el entusiasmo por el capitalismo.

Esta construcción del ser joven y su relación con el conservadurismo en Guatemala tiene sus antecedentes en fenómenos cívico-culturales como las Minervalias, organizadas por el dictador Manuel Estrada Cabrera (1898-1920) en honor de la "juventud estudiosa". Estas fiestas incluyeron la construcción de templos de Minerva en muchos poblados del interior del país y la publicación de álbumes conmemorativos, lujosamente impresos, en los cuales se reprodujeron artículos, mensajes, fotografías y crónicas provenientes de figuras literarias y políticas del mundo liberal latinoamericano, europeo y norteamericano. Rafael Spíndola, Máximo Soto Hall, Enrique Gómez Carrillo, Rubén Darío y José Santos Chocano fueron algunos de los intelectuales que prestaron su nombre a la denominada "religión de la cultura" promovida por el señor presidente en honor de la juventud guatemalteca. Aunque el eje organizador de todo el discurso fue el servilismo a Estrada Cabrera, en las Minervalias se combinaron alusiones a la educación, la pedagogía, la teoría de la historia, la civilización, el nacionalismo, la tradición clásica y, como uno de los autores dice, "el valor de las ideas" y el poder de persuasión de las imágenes. Las Minervalias incluyeron la ejecución de valses, mazurkas, pasos doble, himnos, evoluciones militares, ho- 
nores al pabellón nacional, conciertos de marimba, declamación de poesías, lectura de discursos, quema de bombas, cohetes, entrega de medallas, elevación de globos, carreras de cintas, premios y comida ("lunch”). Las referencias a la niñez y la juventud indígenas son más bien marginales o inexistentes, y a lo sumo en la sección las "Minervales", en los departamentos, en la parte dedicada a Alta Verapaz, se hace mención del premio ganado por María Victoria Motta por su trabajo "Método para lograr la mayor asistencia a la escuela, y el modo más práctico para educar al indígena del departamento". Es interesante destacar en las diversas actividades, el espíritu castrense que exalta la virilidad, la higiene, la disciplina y "el combate al vicio y a la ignorancia". Así, por ejemplo, Enrique Goméz Carrillo, desde el Consulado General de Guatemala en Hamburgo, Alemania, reporta las conclusiones sobre el Congreso de Higiene Escolar celebrado en París, y en el mismo énfasis socio-racial y castrense; E. V. Bergmann, articulista alemán, colabora con la pieza titulada Lo que no cura el fuego lo cura el hierro. Acuerpado en los valores de la superioridad racial, otro autor anónimo a nombre de la legación de Bolivia en Washington, D.C. saluda la iniciativa de Estrada Cabrera con la afirmación: "Creo que los sajones tienen razón al formar jóvenes fuertes con pocos conocimientos, pero bien inculcados" (Álbum de las Minervalias, 1919). Desde fines del siglo xix y durante todo el siglo xx, la juventud indígena estuvo presente en el imaginario de la sociedad dominante cuando se planteó la necesidad de contar con brazos para la agricultura y el ejército, o bien con motivo de la inminencia de revueltas populares y desórdenes públicos (bochinches).

Las investigaciones sobre el universo cultural y político de los jóvenes guatemaltecos tras la firma de los acuerdos de paz, en diciembre de 1996, son bastante escasas. No existen suficientes estudios sobre el papel del racismo y el autoritarismo en el imaginario de los distintos estratos de jóvenes, aunque ambos fenómenos son mencionados frecuentemente en los informes de organismos internacionales y no gubernamentales que promueven la participación organizada de la juventud en la reconstrucción del Estado y de la sociedad. En un informe publicado por la Facultad Latinoamericana de Ciencias Sociales (De Cazali et al.) con el apoyo de la Agencia Sueca para el Desarrollo Internacional (1998), "es significativo que 64.14\% de la población estudiantil investigada respondió que en Guatemala no se respetan los derechos de los jóvenes. El 18\% de los 600 encuestados, se definió como maya o indígena, $48.50 \%$ dijo que las drogas son el principal problema que enfrenta la juventud y $41.04 \%$ opinó que la democracia no sirve para resolver los problemas nacionales".

La mayor parte de las escasas aproximaciones al papel de las ideologías raciales y clasistas en el universo cultural de los jóvenes guatemaltecos han sido realizadas por sociólogos, economistas, politólogos, pedagogos, historiadores o trabajadores sociales (Ángel, 1981; Azmitia, 1992; Bautista, 1993; Carranza, 1992; Hadden, 1997; Rojas, 1980 y Tezaguic, 1993). La perspectiva etnográfica es prácticamente inexistente o muy limitada (Smith, 1996), con lo cual se pier- 
de la posibilidad de contextualizar la información estadística recogida por agencias internacionales y organismos gubernamentales y no gubernamentales. Por ejemplo, René Poitevin, en sus ensayos sociológicos sobre juventud y política publicados con el título de Nadie quiere soñar despierto (2001), advierte entre los jóvenes guatemaltecos apatía, indiferencia, ignorancia, "frustración colectiva" e "individualismo". Los jóvenes, dice Poitevin, son pesimistas respecto al futuro del país; no tienen una utopía que les de el "derecho a soñar y a proyectarse dentro de un sueño colectivo". A pesar de la manera oportuna en que complementa el informe de investigación sobre Los jóvenes guatemaltecos a finales del siglo $x x$, realizado por FLACSO (2000), este trabajo ignora dos factores que son fundamentales para cualquier visión contemporánea sobre la juventud guatemalteca: en primer lugar, no reconoce el hecho de que los indígenas constituyen la mayoría demográfica infantil y juvenil en el país, y en segundo lugar, a pesar de que analiza las relaciones entre juventud, democracia, Estado, educación, sexualidad, drogas, violencia, reconstrucción de la sociedad y el futuro de la región centroamericana; no contiene referencia alguna a los procesos de criminalización de la pobreza que están operando a favor de la marerización y la cholerización de la juventud indígena y mestizo-popular.

Solamente hasta la década de los años noventa del siglo $\mathrm{xx}$, la representación de lo joven en Guatemala empezó a incluir fotografías, pinturas, textos y la voz transcrita o escrita de la juventud indígena de origen maya (Warren, 1999). Sin embargo, cuando se alude a la juventud en Guatemala, se sigue teniendo en mente a los jóvenes citadinos pertenecientes a las capas medias, altas o trabajadoras no-indígenas con acceso a la educación pública y privada. La idea de lo joven en esos términos está vinculada al poder de compra y al capital cultural indispensable para ser reconocido como miembro de una minoría generacional y planetaria (Willis, 1981).

\section{Shumos, choleros y mucos}

Si antes el problema para la civilización y el desarrollo era el problema del indio, ahora el problema lo constituye la shumada, la cholerada y la muchedumbre de mucos desempleados y cuasi delincuentes. Estos desplazamientos simbólicos son evidentes en la producción hemerográfica y en las opiniones de jóvenes, en su mayoría ladinos pertenecientes a estratos bajos, medios y altos de la ciudad de Guatemala, entrevistados por el autor de este artículo entre los años 2001 y 2003.

Ernesto Alvarado, recién graduado bachiller en ciencias y letras en un colegio privado de clase media baja, dice que "todos los que no tienen pisto son shumos". "Son shumos todos los que no son mara caquera, los que son pelados, patanes para hablar, especialmente con las chavas. Los shumos quieren ser todo pero a nada llegan". En la definición de Ernesto, bajo la categoría de shumos entrarían más de tres cuartas partes de los guatemaltecos que "no tienen 
pisto" y que según cifras oficiales viven en pobreza o extrema pobreza. El uso de las llamadas malas palabras, el ser "patanes para hablar" es otro rasgo que convertiría en shumos a hombres y mujeres de todos los estratos sociales que las utilizan en Guatemala y comparten la cultura machista y homofóbica contenida en ellas. En ésta y en otras definiciones de lo shumo como negación de lo caquero, ${ }^{8}$ está presente la crítica al igualamiento y al arribismo social de quienes presumen de un estatus simbólico superior al que les reconocen sus vecinos o conocidos. Quieren tenerlo "todo pero a nada llegan". Shumo entonces es ser pobre, no tener "pisto", pero al mismo tiempo es ser "igualado", querer ser alguien pero sin conseguirlo y además ser "patán" y "pelado".

Nancy Guzmán, cursante del último año de perito contador en una escuela pública, dice que "la palabra shumo se refiere a indio pero de una manera aún más despectiva que indio". Un "shumo", dice Albertina Rodríguez, estudiante en un colegio mixto de la capa media alta, se distingue de alguien que no lo es "por su forma de hablar, de caminar, se nota que es un indígena y por su físico. Por eso dicen: 'Ah, es un shumito' ". Sin embargo, a pesar de ser un sinónimo de indio, la palabra shumo se utiliza, asienta Nancy, "cuando una persona toma actitudes que no son aceptadas en el grupo y se le dice 'Ay, que shumo sos, puro shumito', o sea que es un indio, aunque tal vez la actitud no tiene nada que ver con los indígenas pero es una forma de insultar". Carmen Salazar, alumna de uno de los colegios más caros de la ciudad capital, afirma que ese insulto "se le dice a personas que son necias. Necio, es una persona a la que tal vez uno le dice que haga algo y no lo quiere hacer o se le pide 'haga tal cosa' y está haciendo lo contrario".

En estas definiciones, "shumo" es un indio que se denuncia a sí mismo por su físico, su forma de hablar y de caminar o por su terquedad. Es un término aún más despectivo que indio, aplicable a quienes se empeñan en "llevar la contraria" y a quienes toman actitudes que "no son aceptadas por el grupo". La necedad y el "llevar la contraria" en estas definiciones, recuerda la narrativa colonial que perdura hasta el presente en torno a la "terquedad" de los indígenas. Esta "terquedad" o "necedad" es una construcción estereotipada que a la par de la haraganería, la embriaguez, la idolatría, la suciedad y la vida austera, forma parte del conjunto de las características atribuidas a indígenas y ladinos indígenas populares.

Daniel Sánchez, alumno del último año de magisterio en un instituto público, dice que muco "quiere decir pobre" y "shumo es el natural". Son "palabras discriminativas que se usan como indio y cholero". Ernesto Santizo, estudiante del último año de bachillerato físico-químico en un colegio particular de capa

\footnotetext{
${ }^{8}$ Se denomina caquero al individuo o a la persona "llena de mierdas", un término similar a lo chancle que critica desde abajo a los estratos altos o a los que en sus ansias de escalamiento social presumen de lo que no son o de lo que no tienen. Sin embargo, dentro de esta taxonomía, muchos caqueros no se salvan de ser tildados de shumos o igualados.
} 
media baja, apunta que "los mucos se caracterizan por ser cacos. Casi todos los mucos son indígenas. Un muco y un shumo son la misma babosada aunque un shumo es el que sólo llega a joder la pita y un muco casi seguro que es marero o es largo. Los dos son mara a la que le pela la verga todo, no llevan celular ni ropa de marca. Sólo les gusta andar jodiendo la pita. Estos mucos no van a la escuela y, si van, llegan sólo a chingar". ${ }^{9}$

Úrsula Martínez, alumna de uno de los colegios más caros de la ciudad, señala que "no es necesario que alguien sea un shumo completo pero puede utilizar cosas de shumo y se le puede decir 'ala, qué shumo sos por tus zapatos', o algún detalle de la persona o por las calcomanías en tu carro o algo así". La inclinación "shuma" a llevar la contraria puede ejemplificarse hasta en la forma de vestir. ${ }^{10}$ Por ejemplo, Eduardo Benavides explica la relación entre el ser shumo, el Che Guevara y el ser rebelde en el vestido:

Los jóvenes que lo llevan (al Che Guevara en la playera) son los que hasta cierto punto son mucos o shumos y no deberían vestirse así, ¿por qué?, porque (el Che) fue una persona que fue en contra de la política de su país. Entonces ahora es como tener una playera de... ¿de quién?..., seguro habrán playeras de Osama Bin Laden y ¿por qué? Porque estuvo en contra de Estados Unidos, simplemente fue rebelde en contra de ellos. Entonces a este muco o shumo si se le puede llamar así o como se le llame a esta persona de poca cultura, le gusta ir siempre en contra. "Mirá, vení a las siete", pues entonces llega a las seis y media, ¿por qué?, porque le dijeron que llegara a las siete. Son rebeldes pero no rebeldes en buen sentido de decir vamos a mejorar, sino rebeldes de ir en contra de todo y no les parece nada. ${ }^{11}$

\footnotetext{
${ }^{9}$ Carmen dice que "muco es como shumo, sólo que yo siento que el shumo va más abajo que el muco. Aunque depende. Cada persona lo toma diferente. Pero si son palabras degradantes para cualquiera".

${ }^{10}$ En una ocasión le comenté a Albertina que un estudiante del Colegio Irlandés, uno de los colegios mixtos de la elite capitalina, pensaba que sólo los shumos usan camisas con la cara del Che Guevara y su respuesta fue: "Eso ha de ser porque él se ha de creer mucho. Él se ha de creer mejor. Un shumo es un indígena y es la palabra que más se puede encontrar para discriminarlos: 'Ah, es un shumo'. Es una palabra que denigra totalmente al indigena, sin embargo puede decírsele shumo a alguien que no sea indígena, porque supóngase usted lleva una playera del Che, y dicen 'mirá él carga una playera, ah, pero parece shumo', o sea que usted está imitándolos a ellos (a los shumos)".

${ }^{11}$ Agregando otros elementos a este contexto para una definición múltiple siempre relacionada con el vestido, Nancy Fernández dice que ser muco es más denigrante que ser cholero. "El muco es lo más bajo que existe en la jerarquía. La mayoría se identifican porque también son choleros y están metidos en maras, son personas que usan así playeras flojas, pantalones flojos que llegan a las rodillas, con gorras hacia atrás y muchas pulseras. Hasta sucios se miran". En la misma dimensión del vestido, Úrsula acota: "si usted va para Panajachel, se pone una camisa típica, un morral y un gorrito típico encajan perfectamente con el ambiente, pero si usted se va para Jutiapa, para este lado de oriente, usted se ve mal si se viste de esa manera; se ve mal, se ve como muco". Nancy dice que "a los mucos se les reconoce porque llevan playeras flojas, pantalones flojos que llegan a las rodillas, con gorras hacia atrás y muchas pulseras". Se califica de muco a alguien, según Eduardo, "porque no va vestido como debería, como se viste nuestra generación".
} 
Aquí vale la pena señalar nuevamente las coincidencias que shumos y mucos muestran en relación con el vestido, la falta de "clase", el "buen gusto" y la música. ${ }^{12}$ En cuanto a la música, Eduardo ha establecido una taxonomía discotequera en la llamada zona viva de la ciudad de Guatemala que para él es un microcosmos en donde pueden observarse con claridad las características de todo el espectro que va de los mucos, los choleros y los shumos a los fresas o caqueros pasando por los "normales" y los "intermedios". La observación de Úrsula respecto a que "la gente los acusa de shumos pero a veces disfruta de esas cosas" (de su música) coincide con la afirmación de Eduardo con relación a que "el lugar más alegre es el de los mucos". ${ }^{13}$ Este reconocimiento con visos de interclasismo implica un relajamiento en el self-restraint guatemalteco, un área de intersección entre la muchedumbre "muca" y la denominada gente fina o de alta cultura, que momentáneamente rompe la normalidad impuesta por el conservadurismo dominante, aunque esta ruptura temporal se dé a la par de una guerra simbólica que permanece y normaliza los espacios de la reproducción social jerarquizada en Guatemala. ${ }^{14}$

En estas caracterizaciones y en las sanciones a la transgresión de lo que se considera apropiado o inapropiado destaca el elemento transnacional que complica las percepciones sobre la diferencia y la estratificación social, cultural y

${ }^{12}$ Coincidiendo con Eduardo en relación con la música pero incorporando el factor del carro, Úrsula dice que "una cosa importante es que el carro está lleno de calcomanías siempre y tiene un escape grande que suena bbbbbffffffffffff. Eso es clásico de una persona que se llamaría shumo. Aunque no todos los shumos tengan carro. Pero si una persona mira eso dice 'ala, que shumo ese carro'. Y la música, clásico que en el carro a miles de volumen. Tienen que cargar unas bocinas de "este' tamaño".

${ }^{13}$ Eduardo abunda sobre el tema:

En la zona viva yo podría definir cada uno de los lugares a donde va cada tipo de gente y por qué la música los atrae y los lleva a ese tipo de lugares. El lugar más alegre es el de los mucos porque es donde hay más relajo, bueno supuestamente es el más alegre. Yo pienso que no es donde uno se la pasa mejor pero sí donde hay más ruido, porque quiera que no, esa música es ruido, es ruidosa y como que a la gente le gusta oír ruido [...] En la sexta avenida se mira mucho muco escuchando música muca, ¿por qué?, porque mucha de la población que anda por alli, es gente así, es gente a quien le gusta ese tipo de música ¿por qué?... porque están en contra de algo y tal vez no saben ni en contra de qué, sólo quieren estar en contra de algo y lo más fácil es ponerse en contra del mismo gobierno, entonces ¿están en contra de qué?, de que no les va bien en el negocio o de cualquier otra cosa. La cosa es ir en contra. Como que un muco anda desorientado, bueno creo que por eso es tanta "la contra" contra la gente muca y ello se mira más cuando uno va a lugares como la zona 10 , la zona viva o La Pradera.

${ }^{14}$ Los criterios para definir lo "intermedio" y lo "normal" dependen por otro lado de la manera en que se posiciona la normalidad en contra de la rebeldía. Dice Eduardo, por ejemplo, que "no es normal pasar mañana, tarde y noche, oyendo rock pesado. Eso no es normal. Para Josefina, en música están los roqueros, los mucos y los normales que supongamos son los que escuchan música de Roberto Carlos y cosas asi". 
racial. La forma de llevar la playera, el uso de cadenas, pulseras, pantalones flojos, gorras, zapatos masudos, botas, tatuajes, "ropa típica", y en general el sobreadorno y el decorarse el cuerpo de los shumos, mucos y choleros es muy semejante al acostumbrado por los jóvenes latinos y negros de las grandes ciudades de los Estados Unidos (Valenzuela, 1997).

En una aproximación diferente, Daniel Sánchez, estudiante de bachillerato en un instituto público mixto, dice que shumo y muco son "palabras discriminativas que se usan como indio y cholero", y de forma inesperada agrega, "son insultos que se utilizan bastante en la escuela entre todos pero más que nada entre las mujeres". Según Daniel:

El hombre con poder es la fuente de la envidia y de los sueños de grandeza de las mujeres, y por eso es más fácil que ellas se relacionen con uno por interés del carro o del dinero. Las mujeres tienen más sueños de grandeza que los hombres, y cuando miran algo que desean y les da envidia comparan y ven que hay hombres que tienen más que otros y entonces empiezan a restregárselo a uno en la cara. Tal vez por eso, digo yo.

Esta inusual interpretación de lo shumo y lo cholero como crítica masculina a "las envidias" y "sueños de grandeza de las mujeres", muestra la fuerte presencia de la memoria de desposesión en el universo mental de muchos ladinos mestizos guatemaltecos. Desde la perspectiva de Daniel, los tratamientos denigratorios de shumo y cholero serían en este caso un recordatorio hegemónico de cómo la acumulación de múltiples despojos materiales y simbólicos impiden a muchos hombres mestizos pobres tener pleno acceso al poder patriarcal del ser masculino, amo, patrono blanco y dueño de la mujer que acepta ser parte de sus propiedades. Esa podría ser también la razón por la cual un estudiante de la Escuela de Ciencia Política de la Universidad de San Carlos me dijo que preferiría que lo tratasen de "hijo de la gran puta" en lugar de que le dijeran "cholero". Ambos insultos ("hijo de la gran puta" y "cholero") muestran el arraigo de la memoria de desposesión y la complejidad de las guerras simbólicas que pueden observarse en Guatemala. Y es que la vergüienza o el temor a sufrir humillaciones por el hecho de ser indígena o parecerlo; ser pobre o carecer de acceso a los marcadores de estatus superior reconocidos a nivel nacional y transnacional, o ser señalado de "nuevo rico" ostentoso y de "mal gusto"; hace que cada persona o grupo vivan con el temor constante de ser conceptuados como inferiores.

La normalidad del insulto y el "molestar pero no con ganas de ofender" es semejante a otras justificaciones como el insultar pero sólo para divertirse, o la aclaración explícita de que no se trata de agredir a grupos raciales, sociales o culturales, que aparece en documentos como El cholerímetro, El shumómetro, Algunas señas de que sos un loser, o los "Cantos y chistes y anti-rojos", donde se muestran los repertorios que caracterizan a la jerarquía socio-racista. El documento Mida su cociente shumencial dice, por ejemplo, que "Los Ángeles es la meca de los shumos". De esa forma, los shumos, como los mucos, los mareros y 
los choleros, son una manifestación de la circulación transnacional de bienes, ideas, atuendos, música, formas de saludarse y otros rasgos del gregarismo ritual rechazado por los jóvenes que se asumen como "normales" y de manera mucho más activa por los "burgueses", los "fresas" y los "caqueros".

\section{Visiones caqueras}

El conocimiento del idioma inglés, el poder de compra y la experiencia cosmopolita han sido históricamente propiedad simbólica de la elite y las capas medias altas. Como resultado de la diáspora mesoamericana a los Estados Unidos, un mayor número de guatemaltecos migrantes tienen ahora acceso al cosmopolitismo y a la experiencia de la libertad al interior del mercado. La diáspora en ese sentido ha transnacionalizado las arenas en donde se dirimen, disputan y negocian fronteras de clase y prejuicios raciales y culturales. En estas arenas se critica el consumo y se jerarquiza al consumidor, la mercancía consumida y el lugar donde se consume, abriendo nuevos espacios de confrontación simbólica entre la gente decente y la gente corriente que reciben el impacto de las dinámicas generadas por la migración intranacional y transnacional.

Es particularmente llamativo el hecho de que a pesar de ser un lunar blanco en medio de la masa indígena y "shuma"; la elite blanca y ladina ha sido bastante exitosa en movilizar el repudio del "mestizaje indígena" y las normas no escritas que critican el igualamiento, y organizan simbólicamente la jerarquía que define el lugar de cada quien en sociedad. La crítica del igualamiento ha adquirido mayor fuerza en años recientes a través de narrativas visibles en columnas periodísticas, obras de teatro, páginas de Internet y programas de radio en los que se ridiculiza el arribismo de los "nuevos ricos" y se denigra a quienes pretenden abandonar el lugar que la mentalidad dominante les asigna en la jerarquía nacional y global. Por ejemplo, con el objeto de hacer visibles los prejuicios en contra de "mucos", "shumos", "choleros" y "nuevos ricos", la comediante Mónica Recinos creó el personaje de La Jacky, por Ya Quisieras, una mujer ficticia que goza de gran popularidad entre los estratos altos de la ciudad de Guatemala. En entrevista con el periodista Juan Luis Font (2001), La Jacky dice que no se siente amenazada por la ostentación de riqueza que hacen los nuevos ricos, sino "ofendida". "Es disgusting ver gente muca disfrazada de gente decente. Ver gente que debería ser guardaespalda y anda con guardaespaldas. Que cada quien se ubique donde le toca en la sociedad. La energía de los mucos y la mía no van, por mucho dinero que tengan. Usted sabe que la gente cree que a mí sólo me interesa el dinero, pero no es así, es cosa de ser elegante, asunto de refinamiento", dice La Jacky. ${ }^{15}$

15 - ¿Le dolió que gente como usted dejara de hacer el gobierno? — pregunta Font a La Jacky. - ¿A quién se refiere? 
En esa misma dirección, una pieza de notable valor conceptual para el estudio del socio-racismo guatemalteco en muchos aspectos más directo que la entrevista de Font con La Jacky, es el artículo "Shumada", escrito por Alfred Kalschmitt (1999). Los shumos, según Kalschmitt, son "sucios", "abusivos", "impertinentes", "ladrones", "vulgares", "indecentes", "perezosos" y "desatentos". El shumo no tiene nada que ver con diferencias raciales sino con "el mal gusto" y con "una rebeldía incorregible ante el imperio de la ley," dice el autor. El shumo "es la antítesis del buen gusto", según Kalschmitt. El "gusto" como marcador de clase y el problema de tener o no tener "buen gusto" es parte del cuerpo de ideas y estereotipos que sirven para estigmatizar al "shumo". Es "shumo", sostiene Kalschmitt, quien "satura el avión con olor a pollo frito y llena los compartimentos con apretados bultos". Sin mayor preámbulo ni mediación afirma: "El rap es shumo". "La marimba si no se toca bien se torna shuma. La canción del moño colorado es shuma. La moda extravagante y el body piercing es shumada total". Como en otros espacios, la normalización autoritaria que certifica lo que es apropiado y lo inapropiado en Guatemala es extremadamente intransigente y se proyecta fuera de las fronteras nacionales, como en las críticas a "la moda extravagante, el body piercing", las actitudes de los opositores a Pinochet y las luchas de la izquierda internacional "que también son shumas". Para Kalschmitt:

La izquierda tiene mucha responsabilidad en avivar el fuego de la shumada. Durante años le ha brindado dialéctica barata y teoría perversas para justificar su actitud; especialmente su rebeldía. Y es que la izquierda está llena de shumos. Shumos que incitan a la rebelión social con justificaciones absurdas, como si se pudieran tener derechos sin responsabilidades; y lugar y posición sin trabajo y dedicación.

Kalschmitt asume una "nosotrosidad" que compacta ideológicamente a la elite y moviliza a las capas medias y aun a los sectores populares que se asumen no indígenas. Así dice: "La shumada nos invade", "nos está ahogando con su suciedad y su vulgaridad" (¿a quiénes, nosotros?, ¿a nosotros la "gente decente"?). Y luego se apresura a aclarar que la shumada "no se origina de la pobre-

-A gente como usted de alcurnia y abolengo

—Ah, usted está hablando del Canche (el expresidente Arzú).

- Sí, le hablo del Canche.

—Yo siempre le decía: "Canche, ¿cómo puede gobernar un país con tantos choleros?", y el me contestaba: "El amor a la patria". De veras que se entregó enterito, fue un mártir.

-Últimamente se han oído muchas criticas respecto a que el (Colegio) Americano se ha llenado de gente común.

- Sí, es que eso pasa cuando cualquiera llega a tener dinero. Los new rich son de los que creen que con el dinero pueden comprar cualquier cosa. Y realmente my place no se puede comprar. 0 sea que lo que natura no dio, el instituto central para varones no lo presta.

(Entrevista de Juan Luis Font a La Jacky, 2001) 
za" porque "hay pobres respetuosos y decentes". "Lo shumo", advierte, "no tiene que ver con el racismo porque hay shumos blancos, amarillos y negros".

\section{Midiendo quién es quién en la sociedad guatemalteca}

Un buen ejemplo de cómo se expresan los prejuicios en Guatemala son los documentos anónimos que circulan en el Internet y muestran la estigmatización radical del que aspira a ser clase media, o al que por ser "indio" o "shumo" se le considera incapaz de acceder a los beneficios del mercado y al reconocimiento público. Tanto en "El shumómetro", "El cholerímetro", "Algunas señas de que sos un LOSER", el "Mida su cociente shumencial", o en los Cantos y chistes antirojos se expresan abiertamente y de manera anónima prejuicios de clase, cultura, género y raza con los cuales se intenta disciplinar conductas, mantener el "moral leadership" y producir opinión pública favorable a la reproducción del conservadurismo local.

\section{El shumómetro}

En "El shumómetro", por ejemplo, se mide la condición shuma con base en marcadores tan disímiles como el fenotipo, las "costumbres", los nombres propios, la forma de vestir, hablar, el "trato", la etiqueta, la comida, las características de la vivienda, el manejo de las excrecencias, ${ }^{16}$ las preferencias deportivas, televisivas, musicales, los sitios de entretenimiento, todo lo relativo a los carros, los vínculos reales o imaginarios con las fuentes del poder económico y político y hasta la manera de utilizar el celular y el correo electrónico. El shumo es "hue-

\footnotetext{
${ }^{16}$ La alarma por sonarse la nariz en público, "exprimiéndose los mocos" para después "chicotearlos" al suelo o escupir para "despejar la molestia", es parte del rechazo a lo grotesco de los hábitos higiénicos de la mayoría nacional a quien se considera bárbara e irredimible. El repudio de lo grotesco popular muestra la preeminencia del cuerpo clásico de la moral burguesa y su forma de disciplinar al individuo que aún forma parte de una masa primitiva aferrada al cuerpo antiguo que de manera cotidiana fusiona sus excrecencias con los elementos que integran el orden cósmico (Stallybrass, 1986). Otros aspectos en donde se nota ese celo por imponer el cuerpo clásico y disciplinado de la burguesía, sus orificios y su pánico al contacto físico y a las formas de comunicación que pueden ser consideradas viles y pre-modernas del cuerpo antiguo, es la burla por tomar "el antebrazo a la gente cuando le extienden la mano para saludar", o el llamar la atención de alguien con sonidos como "Chst Chst Chst Chst!", "Shshsht!" o "ah ks-ks-ks!". En esta misma dimensión corporal, el hecho de que una mujer no se rasure las piernas y las axilas o que un hombre "se deje" el "bigote" o la "barba" a pesar de que no le crezcan en abundancia, es motivo también para ser ubicado en esa clasificación denigratoria. Se repudian asimismo las "uñas de cevichera", un rasgo que evoca al amplio espectro de cocineras, verduleras, tortilleras, atoleras, tamaleras, cholojeras, regatonas del mercado, vendedoras de canasto y todas las mujeres que por su condición de trabajadoras vinculadas a la preparación y suministro de alimentos para las ciudades, constituyen el cuerpo femenino de la nación cholera, el bajo pueblo despreciado por la gente decente.
} 
vón, chillón, traicionero, borracho barato, idiosincrático, machista, cobarde, ignorante y por lo general aunque no siempre: delincuente". El shumo así definido se encuentra en contraposición social e ideológica con el macho blanco, patriarcal, masculino, ejecutivo, rico, liberal o conservador que protege, provee, cuida, defiende, y de esa forma gana el derecho a subordinar a los demás, empezando con la mujer que lo admira y le está agradecida. Las características "shumas" recuerdan el estereotipo sobre el indio haragán, "quejita", no confiable, no "bolo fino" que aparece en los ejemplos recogidos por Lisandro Sandoval en su Semántica guatemalense (1940) y por Federico Hernández de León en sus Viajes presidenciales (1941), que describen buena parte de los repertorios que dan cuerpo a las relaciones serviles en Guatemala.

La vigilancia simbólica sobre lo que es considerado socialmente apropiado hacer de acuerdo al origen social y cultural de cada quien, se inicia con el nombre propio que identifica a cada individuo. Así, para los cánones impuestos por la ideología dominante es correcto llamarse Wilmer si se tiene un apellido como Plotcharski, pero alguien con apellido Chonay con el mismo nombre, violenta las reglas no escritas que establecen cuáles son los nombres que "los indios" y los "shumos" se espera utilicen de acuerdo con el capital social y cultural asociado a sus apellidos, un aspecto que ha sido abordado por Amanda Pop en sus investigaciones. Como sujeto transnacional, el "shumo", miembro de una comunidad diaspórica que carece de "educación" y "alta cultura", toma préstamos lingüísticos que lo hacen susceptible de ser estigmatizado dentro de la propia Guatemala como "cholo latino" o "naco mexicano". De esa manera es shumo el que "escucha norteñas (pero a todo volumen...cholersisisIsIsImo)" o el que "se las lleva de 'rappero' [sic] negro (con todo y ademanes de delincuente rappero)". Aquí nuevamente la shumización cruza las fronteras nacionales, criminalizando el ser rapero, negro o no-blanco y por consecuencia delincuente. El retrato del rapero como negro, el negro como rapero y el negro como delincuente corresponde también a la práctica ideológica que denigra las expresiones musicales que pertenecen al universo cultural de los que son considerados "gente corriente". Se es "shumo" por pintar la casa propia de color celeste o azul nacional, y un detalle tan simple que pasaría completamente desapercibido en México o en los Estados Unidos como el "ponerse la camisola de futbol para salir con la familia", es en Guatemala objeto de burla ("iaaahhhh, qué shumo!"). Se es "shumo" si se va por lo menos una vez al mes al estadio Mateo Flores o a La Pedrera "porque es un lugar 'chilero' ". Como si en la ciudad de México alguien fuera social o culturalmente inferior por el mero hecho de asistir a encuentros de futbol en los estadios. Sin embargo, la representación del futbol como deporte shumo no excluye que el sentimiento anti-cholero y anti-shumo se proyecte también en los chistes con que los cremas del Comunicaciones tratan de "choleros" e "hijos de la gran puta" a los rojos del Municipal.

Muchas de las expresiones más virulentas del sentimiento anti-shumo se originan curiosamente alrededor del artefacto más potente producido para el mer- 
cado por la modernidad tecnológica: el automóvil. Así, lo shumo puede definirse a partir de la marca del automóvil que se posee, el color, la música que se lleva, el tamaño de las bocinas y la decoración. El "carro" como eje articulador de la vida cotidiana sirve para exhibir el poder que se tiene o por el cual se es respetado, envidiado, o bien, denigrado y calificado de "indio igualado". El hecho de que ahora haya "un chingo de indios con carro" y de que "cualquier indito anda manejando un BMW", me dijo Jaime Fernández de la universidad Francisco Marroquín, ha venido a modificar el poder simbólico de esa mercancía y la frontera entre los que se supone deben andar a pie o en "camioneta" (transporte público) y los que por su blancura y su poder de compra pueden adquirir carros cuyo costo es inaccesible para la mayoría. Los migrantes a los Estados Unidos que regresan con carros usados, chocados o semi-nuevos para venderlos luego han contribuido a democratizar el prestigio asociado a ser propietario de un vehículo por muy deteriorado que éste se encuentre. Ya que para la elite es imposible restringir el acceso al gran tótem de la modernidad capitalista, se es shumo entonces por colocarle al carro calcomanías con palabras en inglés, polarizarle los vidrios de color "negro guardaespaldas", ponerle luces fluorescentes o intermitentes en diversas partes, instalarle alarma y utilizar ésta como bocina en los semáforos, llevar la música con el volumen muy alto, y otros aspectos que concurren a la crítica del adorno y del sobreadorno, como en la burla de los low riders en los Estados Unidos.

Otro documento de autoría anónima y con una apreciable cantidad de elementos que reproducen la convergencia clasista y racista en Guatemala es "Algunas señas de que sos un LOSER". Este documento, que circula también en Internet, repite varios de los temas abordados por El shumómetro, pero bajo la premisa de que ser loser es ser shumo. Aquí es mucho más claro el castigo a las aspiraciones de escalamiento social utilizando elementos norteamericanos y mexicanos que influyen en las definiciones de lo LOSER LOSER, SOCIAL LOSER, LOSER WANNABE, LOSER INTERNACIONAL, LOSER INGENUO, LOSER NACO, LOSER SNOB, LOSER HIPER SHUMO Y loser pobre, entre otras. Así, por ejemplo, loser loser o social loser ("es en inglés pues!!!") es "quien admira y en día sábado no tiene otra cosa que hacer en su casa que ver en la televisión mexicana Otro Rollo conducido por Adal Ramones". LOSER NACO es quien siguió por televisión las dos ediciones del programa también mexicano, La Academia y tiene como favoritos a los aspirantes Miriam o Yahir. LoSER SNOB es quien no sabe que significa SUV - Sport Utility Vehicle- "y no tiene ni siquiera una". LOSER HIPER SHumo es quien tiene "un carro con una o más calcomanías de No fear, Nitto, Racing Team, cualquier cosa. Com, bad boys, o un Niñito orinando". LOSER POBre es quien tiene "más de cuatro CD's piratas comprados en la 6ta. [avenida] o en un semáforo", y finalmente LosER es la persona quien usa la palabra Loser siendo ella misma LOSER.

En esta conceptualización de lo loser destaca la conciencia sobre la limitada oferta de entretenimiento y las jerarquías del consumo y el poder de compra, especialmente entre quienes tienen que conformarse con la radio comercial y 
las estaciones de la televisión local. El acceso al cable, la computadora, el Internet, el celular, el carro y la ropa de marca se convierten en marcadores de clase con sus respectivos matices particulares. En un contexto donde el manejo del idioma inglés y de sus anglicismos es todavía un marcador de superioridad social, es importante decir el lugar donde uno aprendió o piensa que aprendió el inglés. ${ }^{17}$ En cuanto al fenotipo femenino, se dice que si "te pintás el pelo de canche oxigenada y decís que es natural, no solo sos Loser sino también REмucA". En este caso se restituye el prestigio asociado al cabello rubio, despreciando a quien pretende imitarlo y por imitarlo mal, merecedor de un doble insulto ("RE-MuCA"). ${ }^{18}$ En la cuestión central del carro, alguien es shumo si "tiene por lo menos cuatro familiares que viven en los Estados Unidos y viaja allá mínimo tres veces al año a traer uno o dos carros chocados". Se es shumo además por pensar que "tener un Honda es símbolo de status", ${ }^{19}$ o bien en la vertiente que vincula carros y decencia se es shumo si "su familia tiene más carros de los que caben en el garage, y por lo tanto varios se parquean en la calle, aunque entre todos no sale un carro decente".

Es revelador que al final del documento el gran corolario de su desarrollo conceptual y clasificatorio sea la afirmación, remarcada con un ojo en mayúsculas: “...hay Losers que no son SHumos y pocos SHumos que no son LOSERS!". El sentimiento anti-indígena y la vergüenza por lo indígena alcanzan su clímax en el sentimiento anti-loser. Se normaliza el prejuicio que valora la existencia de los indios puros obedientes y laboriosos y repudia las expresiones ladinas del mestizaje indígena y la cultura de masas consideradas de mal gusto y carentes de "clase". En la misma línea del sentimiento anti-indígena que considera a los shumos responsables del disloque de la sociedad y de sus instituciones, y a tono con los llamados de Kalschmitt en contra de la shumada y del "por qué estamos como estamos", invocado en nombre de una "nosotrosidad" elitista defensora de un guatemalteco esencial que casi siempre es producto de supremacismos y autodenigraciones, el documento dice: "El shumo (a) es la razón por la que estamos como estamos... No tiene nada que ver con el dólar, el gobierno (que está lleno de Shumos, por cierto) ni con la Iglesia, ni los gringos, ni NADA de eso.

\footnotetext{
${ }^{17}$ Así por ejemplo, es seña de ser loser si "cantas" las canciones en inglés "y ni siquiera aprobaste el curso 1 del IGA", o bien, si "no fuiste al IGA sino al CIAV". En esta contradictoria mezcla de localismo y transnacionalismo es evidente que ahora existe un número importante de guatemaltecos indígenas y ladinos de extracción popular que han estado expuestos al idioma inglés, pero que son ridiculizados y desautorizados a utilizar los anglicismos que se supone son patrimonio simbólico de la cuipula social. Lo "cool", el ser "cool", "cute"; usar "bumper stickers", tener su "fashion", ir de "shopping", ser "social loser", "loser wannabe", o el no tener un "SUV", son ejemplo de estas calificaciones que marcan diferencias sociales importantes.

${ }^{18}$ En "El shumómetro", la hispanización de los nombres anglos también es objeto de escarnio: "Te llamas Wilmer, Yadira, Yonatán, Jerson, Giovanni, Rozable, Walter, Wilians, Lesly, Yhajaira, Jessica, Marlon, Beverly, Esteeven (y mal escrito)".

${ }^{19}$ En otra anotación adicional se establece que "los carros favoritos de los choleros siguen siendo el Honda Civic, Nissan Sentra, Toyota Teruel o los ya casi chatarra CRX".
} 
Son los Shumos. Punto". "Son los shumos..." los responsables de "por qué estamos como estamos", ¿quiénes, nosotros? para luego llegar a la conclusión categórica de que "estamos como estamos" por culpa de la indeseable y exterminable masa de shumos.

En otro documento, el "Mida su SQ" (Mida su cociente shumencial) dice por su parte que "la shumitis es una grave enfermedad crónica y altamente contagiosa, de la cual actualmente en Guatemala hay una epidemia incontrolable" y debe tratarse como cualquier afección médica, siempre que se tengan no más de dos síntomas. Si se tienen no más de dos síntomas de shumitis se le deben administrar al paciente "ocho dosis diarias extrafuertes" de "CLASE", así con mayúscula y "para garantizar una mejor absorción, este medicamento viene solamente en supositorios de tres pulgadas de ancho". La terapia anti-shuma ilustra la manera feudal en que la joven patriarquía, y su machismo gay penalizan la falta de "clase", habitando, re-colonizando y poseyendo en la connotación más sexual y patriarcal del término a los considerados choleros, a una buena parte de las mujeres y en general a los pobres especialmente si son indios, mestizos e iletrados.

Otro espacio en donde se manifiesta de manera anónima, bastante cruda y descarnada, la misoginia, la homofobia lúdica, el homosexualismo machista, la analidad, lo escatológico y la creencia en la superioridad de la "clase", son los cantos rojos anti-choleros y los chistes anti-rojos con que los seguidores cremas del Comunicaciones atacan a sus rivales rojos del Municipal. Los cremas feminizan, bastardizan y homosexualizan a los "choleros" rojos. Se retrata a la madre del cholero rojo como prostituta, al cholero como impotente sexual, cornudo e hijo de la gran puta, repudiado por las mujeres, excepto por las prostitutas. En los cantos y los chistes se agrede a la figura femenina ya sea como madre, prostituta, o mujer violada, pero más inteligente que el bastardo cholero. En los cantos anti-rojos al rojo además de adjudicársele la condición de homosexual, se le infantiliza, criminaliza y animaliza, tratándosele literalmente como "mierda", "basura", persona o rival deportivo que merece ser suprimido social y violentamente.

\section{Conclusión}

La exacerbación de los discursos "racialistas" —que aluden a una taxonomía racial, sin necesariamente expresarse como racistas- del conservadurismo guatemalteco a partir de la década de los noventa, muestra en primer lugar el carácter anti-indígena y anti-mestizo popular del llamado racismo, y en segundo lugar manifiesta la pertinencia de asumir el estudio de los discursos y las prácticas que hacen menos a los indígenas, los rurales y los iletrados, especialmente si son pobres e iletrados.

La criminalización de la juventud y la exacerbación de la racialización de la desigualdad en Guatemala es resultado de diversos factores como el miedo ét- 
nico de las capas medias empobrecidas, que estarían reaccionando al temor al igualamiento de los indios y los shumos como resultado de la ampliación del mercado y de la ciudadanía. Estas capas medias acomodadas o empobrecidas desconfían de los indígenas y de las dinámicas del consumo vinculadas a la migración transnacional, que han acelerado procesos de movilidad social y estimulado el temor a la "guerra étnica" de los indígenas (Warren, op. cit.) contra los no-indígenas, o la "rebelión de los choleros" en contra de sus patrones blancos y ladinos. La elite percibe los nuevos esfuerzos democratizadores como un mal síntoma de que para siempre se han ido los viejos tiempos, cuando cada quien dócilmente aceptaba ocupar su lugar en la jerarquía nacional y global.

Además de sus connotaciones abiertamente racistas y clasistas, lo cholero, lo shumo y lo muco son términos equivalentes, utilizados para estigmatizar diversas formas de consumo y cambio cultural, que sintetizan de manera contradictoria tres factores fundamentales de la modernidad cultural guatemalteca: a) El culto al mito del indio puro como sirviente trabajador y obediente; b) el retrato del mestizo ladino como subordinado haragán y rebelde, y c) la manera en que ambas representaciones fomentan el sentimiento anti-indígena y el racismo anti-mestizo indígena de los ladinos, los blancos y los criollos. Si bien shumo, cholero y muco son clasificaciones utilizadas para burlarse de los indígenas y de los plebeyos de piel oscura, puede decirse que esas clasificaciones encarnan el espacio del mestizo no-blanco y del mestizaje negado por la blancura e invisibilizado por la dicotomía indio-ladino. El shumo, el cholero y el muco es el mestizo indígena repudiado por la elite y por el sistema de representaciones que glorifica las purezas raciales, en particular las del "blanco puro" y del "indio puro". "Ser indio pero indio puro", dice una señora que se identifica como maya ante la audiencia de "Casos y cosas", un programa con teléfono abierto en Radio Sonora. O "ser indio, pero de clase", dice otra radioescucha que se presenta como indígena maya en el programa "Buenas Noches, Buenos Días", que se transmite en la misma emisora. Esta valoración positiva de la pureza racial y cultural asociada a la "clase" defendida por personas que no son miembros de la elite, muestra cómo la negación cotidiana del mestizo, o del culturalmente mixto, se da también desde abajo y desde la postura de los indígenas que se consideran "puros". La vergüenza de la "impureza" (indígena, negra, "asiática" o plebeya oscura) contrasta con el culto al "mestizaje eugenésico" invocado para "mejorar la raza", y en buena medida responsable de que no exista un orgullo mestizo capaz de propiciar el desarrollo institucional de una cultura nacional que asuma la herencia indígena y afro-guatemalteca. A diferencia de México, Ecuador, Perú o Bolivia, el repudio del mestizo indígena en Guatemala es más radical, y en ello juega un papel importante la relación entre los valores de la blancura, el imperialismo cultural y el anticomunismo, que han sido estratégicos para la modernización regresiva del Estado y de la economía.

Tanto en "El shumómetro", "Algunas señas de que sos un Loser", el "Mida su SQ" o en los Cantos y chistes anti-rojos se evocan algunas de las ideas de Dur- 
kheim en cuanto a la división del trabajo adoptadas por la sociología funcionalista y estructural-funcionalista. Según estas ideas, por el bien de la sociedad y su armonía, cada quien debe conformarse con el destino que le viene por el lugar y las circunstancias de su nacimiento. Así, si los plebeyos se conformaran con su suerte y los miembros de la elite aprendieran del self-restraint de los plebeyos, unos y otros podrían asumir la armonía que viene de las condiciones "naturales" en que ambos funcionan en sociedad (Willis, op. cit.). Dentro de esa normalización y naturalización de las jerarquías, la virulencia del sentimiento antimestizo en particular puede ser interpretada como reacción de las capas medias que temen ser identificadas como parte de la masa plebeya de indígenas pobres y "choleros". En una reedición del dicho racista de los ladinos populares "soy pobre pero no soy indio", podría decirse "soy pobre o clase media empobrecido pero no soy cholero". Esta vergüenza por lo "indio" y lo "cholero" agudiza la autodenigración ladina y sus irresueltas ansiedades acerca de la supremacía blanca y el poder simbólico de la blancura. Los ladinos de todos los estratos poseen una identidad que es resultado de afirmar una negación, la negación explícita de la cultura que los constituye como mestizos y no-blancos. Este predicamento colonial, post-colonial y neo-colonial es parte de las contradicciones no resueltas de un ser nacional y una ciudadanización ahogadas todavía por el enorme peso de las relaciones de servidumbre, jerarquías y diferencias, reguladas por etiquetas más o menos violentas y autoritarias.

\section{BIBLIOGRAFÍA}

Allen, Theodore W.

1997 The Invention of the White Race. Londres: Verso.

Ángel Madrid, Rosa María

1981 Estudio sobre los valores sociales de las alumnas del 5to. magisterio en educación urbana de establecimientos públicos y privados de la ciudad de Guatemala. Guatemala: Universidad Rafael Landivar (URL), Facultad de Humanidades.

\section{AVANCSO}

2000 "Heridas en la sombra". Percepciones sobre violencia en áreas pobres urbanas y periurbanas de la ciudad de Guatemala. Guatemala: Asociación para el Avance de las Ciencias Sociales.

\section{Azmitia Barranco, Oscar Guillermo}

1992 La formación docente del graduado de magisterio rural y la factibilidad de su participación efectiva en el proceso de su desarrollo. Guatemala: URL, Facultad de Humanidades.

Bastos, Santiago y Manuela Camus

1994 Sombras de una batalla: los desplazados por la violencia en ciudad de Guatemala. Guatemala: Facultad Latinoamericana de Ciencias Sociales (FLACSO). 
Bautista Velásquez, Roberto

1993 Actitudes de indígenas profesionales y no profesionales hacia su idioma materno y cultura. Guatemala: URL, Facultad de Humanidades.

Bonilla-Silva, Eduardo

1997 "Rethinking racism: toward a structural interpretation", American Sociological Review, 62(3): 465-480. Washington: American Sociological Association.

2000 " 'This is a white country': The racial ideology of the western nations of the world system", Sociological Inquiry, 70 (2): 188-214. Alburn: United Chapters of Alpha Kappa Delta International Sociology Honor Society.

Carranza Umaña, Elizabeth

1992 El carácter del estudiante indígena. Estudio realizado en el ciclo diversificado de los establecimientos privados y públicos de la ciudad de Quetzaltenango. Guatemala: URL, Facultad de Humanidades.

Casáus Arzú, Marta Elena

1992 Guatemala, linaje y racismo. Guatemala: FLACSO.

1998 La metamorfosis del racismo en Guatemala. Guatemala: Cholsamaj.

1999 "Los proyectos de integración social del indio y el imaginario nacional de las elites intelectuales guatemaltecas, siglos XIX y XX", Revista de Indias, LIX (217): 775-813. España: Departamento de Historia de América, Instituto de Historia del CSIC.

De Cazali, Lilian, Virgilio Reyes y Víctor J. Moscoso

1998 Perspectivas de los jóvenes sobre la democracia en Guatemala. Guatemala, FLACSO y Agencia Sueca para el Desarrollo Internacional.

Delgado, Richard

1995 Critical Race Theory: The Cutting Edge. Filadelfia: Temple University Press.

FLACSO

2000 Los jóvenes guatemaltecos a finales del siglo XX. Guatemala: FLACSO.

Font, Juan Luis

2001 "La gente es rematerialista y retacaña", El Periódico, Guatemala, 20 de mayo.

Frankenberg, Ruth

1993 White Women, Race Matters: The Social Construction of Whiteness. Minneapolis: University of Minnesota Press.

Goldberg, David

1990 Anatomy of Racism. Minneapolis: University of Minnesota Press.

1995 "The semantics of race", Ethnic and Racial Studies, 15(4): 543-69. Filadelfia: Taylor and Francis. 
Hadden, Gerald

1997 Teenage Refugees from Guatemala Speak Out. Nueva York: Rosen Publishing Group.

Harrison, Faye V.

1995 "The persistent power of 'race' in the cultural and political economy of racism", Annual Review of Anthropology, 24: 47-74. Baltimore: Johns Hopkins University.

Hernández de León, Federico

1941 Viajes presidenciales. Guatemala: Tipografía Nacional.

Horne, Gerald

1999 "Race from power, U.S. foreign policy and the general crisis of 'white supremacy'", Diplomatic History, 23(3): 437-461. Cambridge, MA: Society for Historians of America Foreign Relations, Blackwell Publishers.

Kaltschmitt, Alfred

1999 "Shumada", Siglo XXI, Guatemala, 11 de octubre.

Kang, Liu

1997 "Hegemony and cultural revolution", New Literary History, (28): 69-86. Baltimore, Maryland: The Johns Hopkins University Press.

Lipsitz, George

1999 The Possesive Investment of Whiteness. How People Profit from Identity Politics. Filadelfia: Temple University Press.

Omi, Michael y Howard Winant

1986 Racial Formation in the United States: From the 1960s to the 1980s. Nueva York: Routledge.

Pérez Sáinz, Juan Pablo

1990 Ciudad, subsistencia e informalidad: Tres estudios sobre el área metropolitana de Guatemala. Guatemala: FLACSO.

1991 Ciudad de Guatemala en la década de los ochenta: Crisis y urbanización. Guatemala, FLACSO.

Poitevin, René

2001 Nadie quiere soñar despierto. Guatemala, FLACSO.

Press Giroux, Henry

1997 "White squall: Resistance and the pedagogy of whiteness", Cultural Studies, 11(3): 376-389. Durham: Duke University Press.

Quiroa, Marco Augusto

2001 "El reino de las maras", El Periódico, Guatemala, 2 de diciembre. 
Roberts, Bryan

1968 "Politics in a neighborhood of Guatemala city", Sociology, 2 (2): 185-203. Londres: Sage Publications.

Roberts, Bryan

1970 "Urban poverty and political behavior in Guatemala", Human Organization, 29(1): 20-28. Oklahoma: Society for Applied Anthropology Publications.

Roediger, David

1995 Towards the Abolition of Whiteness: Essays on Race, Politics and the Working Class History. Londres: Verso.

Rojas Angulo, Roberto

1980 Estudio comparativo del $\mathrm{Cl}$ entre un grupo de universitarios indigenas y otro no indígena. Guatemala: URL, Facultad de Humanidades.

Sandoval, Lisandro

1940 Semántica guatemalense. Guatemala: Tipografia Nacional.

Smith, Carol A.

1996 "Myths, intellectuals and race/class/gender distinctions in the formation of Latin American nations", Journal of Latin American Anthropology, 2(1): 148169. Florida: Florida International University, College of Arts and Sciences, Latin America and Caribbean Center (LACC).

Stallybrass, P. A. W.

1986 The Politics and Poetics of Transgression. Ithaca, Nueva York: Cornell University Press.

Tezaguic Tohón, Joel

1993 Actitudes de estudiantes mayas de educación media hacia sus idiomas. Guatemala: URL, Facultad de Humanidades.

Valenzuela Arce, José Manuel

1997 Vida de barro duro: cultura popular juvenil y graffiti. Guadalajara: Colegio de la Frontera Norte.

Warren, Kay B.

1999 Indigenous Movements and their Critics, Pan-Maya Activism in Guatemala. Nueva Jersey: Princeton University Press.

Willis, Paul

1981 Learning to Labor: How Working Class Kids Get Working Class Jobs. Nueva York: Teachers College Press. 